\title{
Psychiatric training
}

\author{
Letter from Brazil
}

John Dunn

The arrangement of medical services in Brazil is more akin to that of the USA than the UK. Private practice predominates but with a safety net of state funded hospitals. The majority of doctors working in state hospitals have contracts for 20 hours per week and are very poorly paid and they often have two or three jobs to compensate. These usually include working in a private clinic for part of the week and perhaps doing a period of on-call at another hospital. Some state hospitals are unable to fill vacant posts and there are frequent television reports of casualty departments having to close due to a lack of medical staff.

The medical school system is similar to that of southern European countries, such as Italy. The total number of medical school places is not centrally controlled, but medical schools with high reputations do limit the number of students they admit each year. The medical school course lasts six years with clinical attachments from the third or fourth year. In the fifth and sixth years students are directly involved in patient management, under the supervision of a consultant, and are called interns or 'internos'. There is no final MB exam but there is a system of continuous assessment with exams in the pre-clinical years and clinical evaluations thereafter. After satisfactorily completing the course students are awarded a diploma, but must also apply to the state licensing boards to be able to work in the local state hospitals.

The newly qualified doctor can then go on to train in his or her speciality of choice. This stage is known as the residency and generally lasts two years, but some centres have introduced an optional third year; at the Escola Paulista de Medicina this third year was made mandatory from the beginning of 1994. The psychiatric residency described here is based on the Escola Paulista de Medicina in São Paulo and the attached Hospital São Paulo but residencies vary considerably, probably more so than in the UK where guidelines and monitoring by the Royal College of Psychiatrists have led to some degree of conformity.

In the first year there are three clinical attachments each of four months duration: in-patients, out-patients and the 'pronto socorro' which is equivalent to a casualty department. During the first year the resident is expected to take on at least two psychotherapy patients, one for weekly and the other twice weekly therapy. Many residents also choose to go into therapy themselves. The first attachment is to the in-patient unit which is an 18-bedded female ward, male patients being treated at a separate hospital. The resident works in a team of four with a trainee psychologist, social worker and occupational therapist and they are responsible for a small group of patients. Inevitably in such a setting there is some blurring of professional boundaries. The resident receives supervision from a consultant on an almost daily basis.

The second attachment is in the out-patient department. Out-patient services are considered more of a speciality than in the UK. Greater emphasis is put on treating patients in this setting, admission being seen as a last resort. In Brazil, children tend to live with their families until they get married; as a consequence families are generally more available, although not always more willing, to look after sick members at home than they are in the UK. The resident does regular general psychiatric out-patient clinics with consultant supervision and is also responsible for providing a liaison psychiatric service to the rest of the hospital.

The third attachment is in the casualty department ('pronto socorro'). The resident sees all psychiatric cases directly and decides on the immediate management. Each major speciality has a senior doctor (chefe de plantão) avallable in the department for advice and supervision. When the resident is attending lectures (about three times per week for one and a half hours) or receiving supervision the chefe de plantão is the only psychiatrist in the department. This is a system the UK would do well to follow, as a common complaint among UK psychiatric trainees is that clinical demands prevent them from attending academic sessions. After doing two months as a psychiatric resident, the trainee has one month's holiday and then returns to do one month as the resident neurologist, also in the 'pronto socorro'.

The academic component of the first year consists of three concurrent courses. The subjects are psychopathology, psychopharmacology and psychotherapy. Seminars are held three times a week and last about one and a half hours. There 
is a weekly departmental meeting with multidisciplinary case presentations and lectures on more theoretical aspects of psychiatry.

Residents do on-call approximately three times every 14 days. On week days the on-call period starts at 6 p.m. and finishes at 8 a.m. and at weekends starts at 8 a.m. and lasts until 8 a.m. the following day. Normal clinical duties continue, so on a weekday residents may work continuously for $\mathbf{4 4}$ hours. Salaries are low, residents earning the equivalent of about US\$300 per month or less. Inflation is currently running at over $40 \%$ per month so the salary rapidly devalues with time. As a consequence, salaries are readjusted on a regular basis. Until recently this was only done every four months but in October 1993 all residents in federal hospitals went on strike until the government agreed to move residents onto a different pay level with more frequent readjustments. A recent television report indicated that many street vendors selling magazines, sweets and fruit in the locale of one hospital were earning more than the doctors working inside.

Many doctors who come from Säo Paulo continue to live with their families during the residency period; doctors who do not have families locally can opt to live in hospital quarters. The apartments are quite reasonable, with kitchen, sitting room, TV and bathroom facilities; the only drawback being that shared bedrooms (sharing with at least one other person) are the norm. Either way, motels offering overnight or by the hour services for courting couples are big business in Brazil. Residents are also allowed to eat in the hospital canteen free of charge, but the quality of the food is probably on a par with that in state hospitals throughout the world.

In the second year there are a further three clinical attachments, each lasting four months: in-patients; out-patients/crisis clinic; and liaison psychiatry/child psychiatry. The residents can now do clinics in various psychiatric subspecialities including schizophrenia, affective disorders, and substance misuse. Trainees continue to see patients for psychotherapy on a weekly and twice weekly basis. Residents are encouraged at this stage to visit one of the poorer areas (favelas) outside of São Paulo City, and meet people in their homes. The purpose is not so much to provide psychiatric treatment but simply to talk to the people and try to understand their lives and problems.

The academic course in the second year follows the same pattern as the first with three concurrent courses in child psychiatry, social psychiatry, and the history of psychiatry. During the second year the resident stops doing on-call and works a $\mathbf{4 0}$ hour week. However, because of the low salaries, many opt to 'moonlight' at other hospitals to earn extra money.
From the beginning of 1994 the residency was extended to three years. The new third year consists of attachments which are obligatory and others which are elective, most of the attachments run concurrently for a fixed number of sessions per week and last either the full year or for six months. Undertaking psychotherapy with both an individual case and a group is obligatory and these activities run for the full year. Outpatient child psychiatry is also obligatory and lasts for the full year. There are three six-month attachments in the affective disorders clinic, the schizophrenia clinic and the substance misuse service, two of which run concurrently. There is an elective attachment for eight hours per week which lasts the full year; the resident is able to choose from the full range of activities which take place in the department. Also two new courses have been introduced to the academic programme: scientific methodology and an advanced psychotherapy course.

There is no exam at the end of the residency, but the resident receives a certificate of specialisation. The newly qualified specialist can work in a private clinic as an independent practitioner, continue to work in the state hospital system, move into academic psychiatry or try to combine two or more of the above options.

As in the UK, residents complain that there is no time to undertake research during clinical attachments and few do so. However, once the residency is completed some doctors go on to do Masters degrees and PhDs. Some doctors who do so choose to study abroad and academic experience in the USA, UK and Canada is highly valued. According to a recent publication from Brazil, there were 600 Brazilians doing postgraduate studies in $1989 / 90$ in the UK alone (separate figures were not available for those doing post-graduate medical studies) (Dratcu \& Misch, 1992). Funding to do research abroad can be obtained from a variety of sources, including foreign organisations such as the British Council, which has offices in São Paulo, and Brazilian organisations such as the government-funded CNPq (Conselho Nacional de Desenvolvimento Cientifico e Tecnológico). The latter also considers applications from foreign doctors who are interested in doing research and teaching in Brazil.

\section{Reference}

DraTCU, L. \& Misch, P. (1992) Panorama da profissão e do ensino medicos na Gra Bretanha. Revista ABP - APAL 14. 75-80.

John Dunn, CNPq Visiting Researcher, Departamento de Psiquiatria, Escola Paulista de Medicina, Rua Botucatú, 740, São Paulo-SP, Brazil, 04023-900 